\title{
Why there were few cases of coronavirus disease 2019 in Libya during the first two months of the pandemic?
}

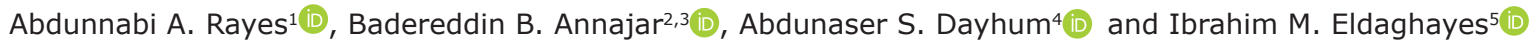 \\ 1. Department of Internal Medicine, Faculty of Medicine, University of Tripoli, Tripoli, Libya; 2. Department of Public \\ Health, Faculty of Medical Technology, University of Tripoli, Tripoli, Libya; 3. National Center for Disease Control, \\ Tripoli, Libya; 4. Department of Preventive Medicine, Faculty of Veterinary Medicine, University of Tripoli, Tripoli, Libya; \\ 5. Department of Microbiology and Parasitology, Faculty of Veterinary Medicine, University of Tripoli, Tripoli, Libya. \\ Corresponding author: Ibrahim M. Eldaghayes, e-mail: ibrahim.eldaghayes@vetmed.edu.ly \\ Co-authors: AAR: drabdurayes@gmail.com, BBA: bbannajar@yahoo.com, ASD: adayhum@yahoo.com \\ Received: 02-08-2020, Accepted: 06-10-2020, Published online: 06-11-2020
}

doi: www.doi.org/10.14202/IJOH.2020.160-164 How to cite this article: Rayes AA, Annajar BB, Dayhum AS, Eldaghayes IM (2020) Why there were few cases of coronavirus disease 2019 in Libya during the first two months of the pandemic? Int. J. One Health, 6(2): 160-164.

\begin{abstract}
Coronavirus disease 2019 (COVID-19) is a pandemic that affected almost all countries worldwide with more than $29,439,120$ confirmed cases and 932,486 deaths recorded till on September 14, 2020. However, on May 25, 2020, after 2 months from the first reported case of COVID-19 in Libya, the country was among very few countries in the world that had very few cases of COVID-19 with a total of 75 confirmed cases and three deaths during the first 2 months since the detection of the first case on March 24, 2020. Based on the global epidemiological pattern of the disease, the magnitude of COVID-19 in Libya could have been much worse. However, the reality is eccentrically different and the epidemiology exhibited different scenario with very few cases being recorded during the first 2 months of pandemic in Libya. In this article, a review of COVID-19 situation in Libya is presented with thoughts about the potential reasons that could explain the very few cases of COVID-19 in the country in context with the global figures of the pandemic.
\end{abstract}

Keywords: coronavirus disease 2019, epidemiology, incidence, Libya, pandemic.

\section{Introduction}

The National Centre for Disease Control (NCDC) of Libya is the main entity responsible for dealing with all public health issues including maintaining national health security. It, therefore, took the lead to coordinate most actions to compact coronavirus disease 2019 (COVID-19).

By May 25, 2020 there were only 75 confirmed cases (Figure-1) out of 5154 tested samples collected mainly from suspected cases and from people in contact with confirmed cases [1].

Since the first confirmed case of COVID-19 in Libya on March 24, 2020 [2], the epidemiologists have started their work by applying some epidemiological modules to predict the behavior of COVID-19 in Libya. With this regard, and in terms of how many cases of COVID-19 in Libya would be expected to be detected in the next weeks, a recent study showed two scenarios using the differential equation model (SIR model) based on currently available data [3]. The first scenario, in case of no social distancing measures, was implemented, and showed that the expected number of cases could be around 1,903,345. The disease will reach its peak around mid of May 2020 and patients

Copyright: Rayes, et al. This article is an open access article distributed under the terms of the Creative Commons Attribution 4.0 International License (http://creativecommons.org/licenses/ by/4.0/), which permits unrestricted use, distribution, and reproduction in any medium, provided you give appropriate credit to the original author(s) and the source, provide a link to the Creative Commons license, and indicate if changes were made. The Creative Commons Public Domain Dedication waiver (http:// creativecommons.org/ publicdomain/zero/1.0/) applies to the data made available in this article, unless otherwise stated. who would require admission to ICU would be around 121,814 .

The same study [3] showed the second scenario when the social distancing measures were applied; it showed that the expected number of cases would be around 329,822. The disease will reach its peak around the beginning of August 2020 and patients who would require admission to ICU would be around 13,192.

In the Libyan situation, where the conflict is ongoing for years, with weakness of the health systems and limited access to even the most basic medical care services, ideally, COVID-19 was expected to hit the country as a disaster. However, what was proposed and predicted by epidemiologists for Libya using different modules does not reflect the real situation for the disease in Libya. There must be many factors and reasons that led to these findings in Libya when comparing the disease pattern with other countries.

The aim of this review was to evaluate COVID-19 situation in Libya during only the first 2 months of the pandemic in Libya with thoughts and potential reasons that could explain the very few cases of COVID-19 in the country before behavior of the disease has changed in the following months and reporting of hundreds of confirmed cases on a daily basis. The small number of reported cases during the first 2 months of COVID-19 in Libya can be attributed to the following reasons:

\section{Early Declaration of the State of Emergency}

A very important step that was taken by the government when the president of the Government 
of National Accord (GNA) declared on March 14, 2020 , the state of emergency in regard of combating COVID-19 even before the detection of the first case in the country (March 24, 2020). He further imposed a set of precautions and preventive measures as on March 17 , to prevent the spread of the virus, the GNA closed the country's borders, suspended flights for 3 weeks and banned foreign nationals from entering the country; moreover, schools, universities, cafes, restaurants, mosques, and public gatherings have also been closed. Furthermore, on March 30, 2020, the GNA announced the release of 466 detainees in Tripoli, as part of an effort to stop the spread of the virus in prisons.

\section{Country Isolation}

Following China report to the WHO on the coronavirus outbreak on December 31, 2019, many countries reported their first cases of the disease in January 2020. The first cases detected in many countries were mainly in travelers who have arrived from Wuhan, China. As an example, on January 8 and 13 the first two cases of COVID-19 in Thailand were detected in two women who were in China and just arrived from Wuhan [4].

At the beginning of the pandemic and when the number of cases of infection with COVID-19 has continued to increase, many countries have established restrictions regarding travelers who have recently visited China with many airlines stopped operating to and from that country. Before the travel ban, about $86 \%$ of the internationally imported cases of COVID19 were originated from people who have been in Wuhan, China [5].

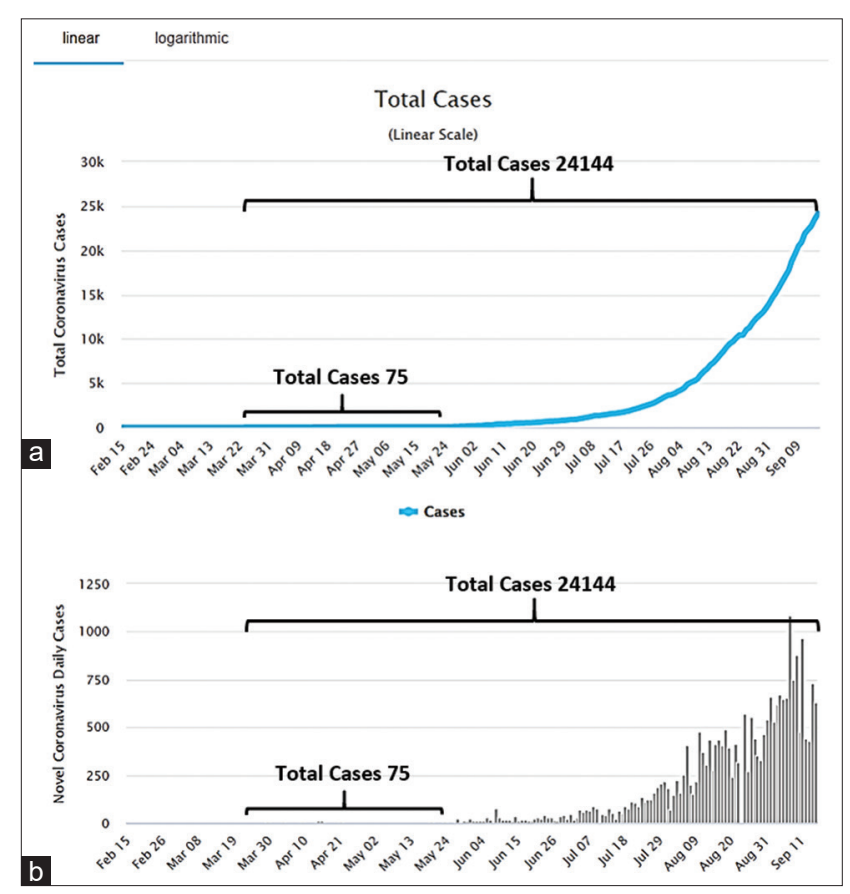

Figure-1: Total number of confirmed cases of coronavirus disease 2019 (COVID-19) in Libya. Only 75 cases during the first 2 months, and 24,144 cases till September 14, 2020. (a) Total number of COVID-19 cases in Libya. (b) Daily new cases in Libya.
Libya, as a country with recent conflict and war, has led to no international airlines being operating in Libya. Apart from a few local airlines that have few flights daily to Tunisia, Egypt, Jordan, and Turkey with no direct flights to China or Europe. Hence, the risk of the virus introduction into Libya was very low, and this can give an explanation that the first confirmed case on March 24 in Libya was reported in an older man who was visiting and just arrived from Saudi Arabia.

\section{Few Tests Being Undertaken}

Till May 25, only 75 confirmed cases out of 5154 tested samples from all over the country. Only three cases (females) have died and 35 cases were recovered [1]. At the beginning, there was a shortage of RT-PCR materials and swabs, and the NCDC decided to test only suspected cases. Once any suspected case was confirmed then all contacts of the positive case will be traced by the investigation team of the NCDC and samples will be collected and tested in the reference laboratory of the NCDC. This action by NCDC could have led to missing of many asymptomatic and mild cases.

The number of tested samples in Libya was very little compared to other countries. For example, as for May 25, total COVID-19 tests carried out per 1000 people [6], showed that in Italy it was about 57 tests per 1000 people, in USA about 42 tests/1000 people, in Canada about 39 tests per 1000 people, in Saudi Arabia about 20 tests/1000 people, in Tunisia about 4 tests per 1000 people, and in Morocco about 2.5 test/1000 people, whereas in Libya, it was only 0.75 tests/1000 people in the same period. However, in the following months, the number of tested samples has been increased to average between 3000 to 4000 samples per day.

\section{Libyan Population Age}

According to the WHO, older people in particular and also people of all ages with pre-existing chronic medical conditions such as diabetes mellitus, hypertension, heart disease, lung disease, or cancer appear to develop serious COVID-19 illness more often than others [7]. About 95\% of deaths from COVID-19 were among people aged 60 years and older. More than $50 \%$ of all deaths were among people aged 80 years or older.

It is also well known from the literature that eight out of ten deaths are occurring in individuals not only with at least one underlying comorbidity, in particular, those with cardiovascular diseases/hypertension and diabetes but also with a range of other chronic underlying conditions [8].

In Libya, the prediction of total Libyan population in 2020 was estimated to be $6,871,286$ inhabitants, where about $6.7 \%$ of this total population aged 60 years and older. This means that more than $93 \%$ of Libyan population is under 60 years (Figure-2). This 


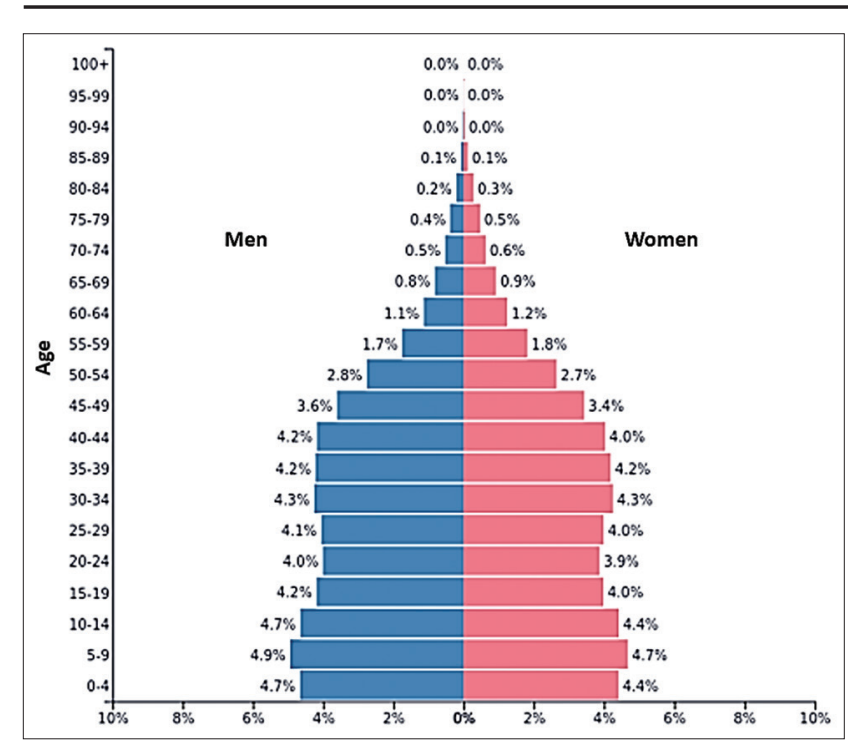

Figure-2: Percentage of Libyan population according to the age.

could explain the higher mortality rate in Italy where $23.1 \%$ of the total population in Italy was estimated to be aged 65 years and older [9]. With no vaccine or drug has been approved for COVID-19, still the immunity, which is higher in young people, is one of the key players in resisting the coronavirus infection.

\section{Country Instability}

In areas where the military conflicts are present, it would be expected to have an urgent need to strengthen the COVID-19 response for the most vulnerable populations, where there is limited infrastructure for the response to COVID-19 [10]. However, due to the current war and instability of Libya, the movement is restricted. This can be seen in a positive way, as it would reduce the risk of spreading of the virus within the country.

As mentioned above that the country was isolated with no national nor international flights which helped to isolate many cities from each other, especially regarding the absence of flights between the eastern and the western parts of Libya and almost complete terrestrial movement between these two parts, knowing that only four cases have been reported in the eastern part of the country until the date of May 25 . The conflict and country instability have helped to prevent the spread of the disease. The main bulk of the positive cases as reported on May 25 was detected in Tripoli city with 50 confirmed cases, followed by Misrata city with ten confirmed cases, Benghazi city with four confirmed cases, and Zliten city with three confirmed cases, whereas the remaining cases were scattered in some cities in the western parts of Libya within $75 \mathrm{Km}$ distance from Tripoli [11].

\section{People Education and Social Distance}

As the disease started in Libya in late March, this led to many educational and awareness campaigns on COVID-19 being carried out throughout the country such as lectures, TV, and radio interviews. These campaigns were done by professional and expert people especially from different Libyan universities through active lectures, social media, and online meetings. This had a great impact on Libyan people who were well aware of many COVID-19 aspects such as its symptoms, viral transmission, and prevention methods. In addition, the early implementation of social distancing measures had good impact on the disease by breaking the chain of virus transmission. Social distancing measures that were proposed by the NCDC and implemented by the government, even before the reporting of the first case and within the first two months, could have played a significant role in reducing the spread of the virus in Libya.

\section{BCG Vaccination}

BCG vaccination has been reported to offer broad protection against respiratory infections in general. Data showed that countries without universal BCG vaccination policies, for example, Italy, Nederland, and USA, were severely affected with COVID-19 compared to other countries with universal and long-standing BCG policies such as Libya [12]. Countries that do not carry out BCG vaccination within their vaccination program had 10 times higher incidence of COVID-19 (358.4 per million) when compared with countries that apply the BCG vaccination (38.4 per million) [13]. In a recent study concluded that routine infant BCG vaccination coverage in young generation had a significant impact on prevention of local COVID-19 spread in Japan [14]. However, other studies reported that BCG vaccine does not have any influence on the incidence of COVID-19 [15].

In Libya, the BCG vaccine was introduced in early 1950s. Libya was the first country in the region to introduce BCG vaccination on massive scale as in 1971 Libya has passed a legislation that made neonatal BCG vaccination compulsory which led to $99.9 \%$ BCG vaccination coverage (Sadeg Behelil, Head of vaccination program in Libya, personal communication). The increasing number of positive cases in Libya in the following months could support the reports claiming that BCG vaccine has no role in protection from COVID-19.

\section{Virus Strain}

It is well known that there are many coronavirus strains circulating in the world. In a recent study, genetic analyses of 86 genomes of SARS-CoV-2 were performed and revealed many mutations and deletions on coding and non-coding regions. These observations provided evidence of the genetic diversity and rapid evolution of this novel coronavirus [16]. Some of these strains could be virulent and has a greater impact as seen in many European countries [17], whereas other mutations could make the virus less virulent. 
One of the scenarios that could lead for a pandemic to end is that the circulating viruses could have mutations, where these mutations can lead the virus to lose its virulence and become a weak virus. The whole-genome sequence is undergoing by NDCD Reference laboratory, once the sequencing of the viral genome is done then lots of data on viruses circulating in Libya would be available.

\section{Herd Immunity}

This is based on the fact that allowing the virus (SARS-CoV-2) to be spread between people to increase population immunity (60-70\% immunity) [18]. Herd immunity has been proposed as one of the mechanisms that can act to reduce the disease burden on the community but many other studies doubted its efficacy in COVID-19.

There was a huge feedback from Libyans claiming that severe cold symptoms similar to COVID-19 were reported in many cities in Libya last winter. This can be proved or excluded once a serological survey is done in different populations to look for evidence of ongoing or past infection with this virus. Various serological surveys are being planned by many organizations in Libya including some universities and NCDC, and some results in Tripoli, Misrata, and Benghazi showed very little or no immune response to COVID-19 in tested samples (data not published); hence, the herd immunity could be excluded in Libya. Moreover, with the increase number of confirmed cases in Libya from June to September (Figure-1), the herd immunity factor is excluded.

\section{Climatic Conditions}

Libya is a huge country with an area of almost $1,800,000 \mathrm{~km}^{2}$ and located in the North of Africa both the Mediterranean Sea and the desert affect Libya's climate. In winter, the weather is cool with some rain in the coastal areas. Temperatures in the summer can reach $50^{\circ} \mathrm{C}$ during the day but more commonly are around $40^{\circ} \mathrm{C}$.

Climatic conditions could have some effect on viral activity and infectivity. The temperature and relative humidity have an influence on the effective reproductive number ( $\mathrm{R}$ values) of COVID-19. A recent study [19] showed that an increase in the temperature by $1{ }^{\circ} \mathrm{C}$ has reduced $\mathrm{R}$ value by 0.023 in China and 0.020 in the USA, whereas increasing relative humidity by $1 \%$ has reduced $\mathrm{R}$ value by 0.0078 in China and 0.0080 in the USA.

Another study [20] showed that higher rainfall could increase the disease transmission; however, COVID-19 mortality showed no significant association with temperature.

Considering the existing scientific evidence, warm and wet climates seem to reduce the spread of COVID-19 but without certain conclusion. However, many factors could play a role in disease transmission and the climate alone would not explain most of the variability in disease transmission [21].
Although warmer weather may affect the transmission of SARS-CoV-2, the global pandemic of COVID-19 in many countries with different climate conditions would suggest that seasonality cannot be considered as a key modulating factor of COVID-19 transmission, further studies are needed [22]. In Libya, the hot weather has no influence on the disease spread as increased number of confirmed cases was reported during the summer season (Figure-1).

\section{Expatriates}

As in other countries, we have some expatriate population in many countries that started to come back since the beginning of May, 2020. They were residing in many countries but mainly in Turkey, Egypt, and Tunisia. Although many preventive measures were implemented by the Libyan authorities to reduce the risk of anyone of them arriving with infection, these measures may not be followed strictly and hence the risk of importing a new viral strain to Libya is imminent that could lead to a different scenario of this illness especially knowing that these repatriated people are living in many cities all over the country that could result in spreading the disease to new areas and cities in Libya.

Recently, some expatriates were found to be SARS-CoV-2 positive, despite following strictly all the quarantine measures implemented by the Libyan authorities before coming back to Libya, including 2 weeks of hotel quarantine, having two RT-PCR samples tested negative for the virus, and self-home quarantine in Libya for 14 days and another RT-PCR test.

These measures were followed by those who returned from Turkey where very few people were detected to be positive in Libya and only one expatriate infected patient was found to infect six of his contacts, while the others were isolated in isolation centers and did not infect anyone. The implemented measures were not followed by the expatriates in Egypt who were kept in institutional quarantine centers for 14 days and many of them were found to be infected and some of them were released before the quarantine period. According to the investigation team of the NCDC, unfortunately, many of these people did not follow these recommendations of self-home isolation after being released from the quarantine centers and this would change the original reasonably quite situation of COVID-19 in the country, transmitting the virus to other cities and involving older people and patients with chronic illness, making the situation worse.

\section{Conclusion}

Finally, we put some hypotheses for the low incidence of COVID-19 among Libyans during the first 2 months of the outbreak, based on some theories that have been raised in the literature, but after reviewing our data of COVID-19 cases and following the pattern of the pandemic in Libya in the last few months, we believe that the most important factor for the few cases in the beginning of the epidemic was the segregation of the cities and the 
war-imposed restriction in the movement of the people between the cities and even in the capital Tripoli during the war. The picture of COVID-19 in Libya has changed dramatically with alarmingly increased numbers of confirmed cases that reached 24,144 cases till September 14, 2020. This review article documented and highlighted how the pandemic has changed in Libya from very few cases during the first 2 months of disease in the country to hundreds of cases every day lately. This review article would help the decision-makers to review all discussed points and to understand what are the major reasons for the spread of COVID-19 in Libya, and why the number of confirmed cases has changed from daily few cases during the first 2 months of the pandemic in the country to hundreds of confirmed cases every day to control the spread of the disease in Libya.

\section{Authors' Contributions}

All authors contributed equally to the design of the review, writing, and revision. All authors read and approved the final manuscript.

\section{Acknowledgments}

The authors did not receive any funds for this study.

\section{Competing Interests} interests.

The authors declare that they have no competing

\section{Publisher's Note}

Veterinary World (Publisher of International Journal of One Health) remains neutral with regard to jurisdictional claims in published institutional affiliation.

\section{References}

1. National Center for Diseases Control. (2020) COVID-19 Updates in Libya. Available from: https://www.covid19.ly. Retrieved on 25-05-2020.

2. Elhadi, M., Momen, A.A. and Abdulhadi, O.M. (2020) A COVID-19 case in Libya acquired in Saudi Arabia. Trav. Med. Infect. Dis., (in press) https://doi.org/10.1016/j. tmaid.2020.101705.

3. Gibreel, T. (2020) Prediction and Analysis of Covid-19 Epidemic in Libya. Available from: https://www.scribd. com/document/455005305/Prediction-and-Analysis-ofCovid-19-Epidemic-in-Libya. Retrieved on 02-05-2020.

4. Okada, P., Buathong, R., Phuygun, S., Thanadachakul, T., Parnmen, S., Wongboot, W., Waicharoen, S., Wacharapluesadee, S., Uttayamakul, S., Vachiraphan, A., Chittaganpitch, M., Mekha, N., Janejai, N., Iamsirithaworn, S., Lee, R. and Maurer-Stroh, S. (2020) Early transmission patterns of coronavirus disease 2019 (COVID-19) in travellers from Wuhan to Thailand, January 2020. Euro. Surveill., 25(8): 2000097.

5. Chinazzi, M., Davis, J.T., Ajelli, M., Gioannini, C., Litvinova, M., Merler, S., Piontti, A.P., Mu, K., Rossi, L., Sun, K., Viboud, C., Xiong, X., Yu, H., Halloran, M.E., Longini, I.M. Jr. and Vespignani, A. (2020) The effect of travel restrictions on the spread of the 2019 novel coronavirus (COVID-19) outbreak. Science, 368(6489): 395-400.

6. Our World in Data. (2020) Available from: https://www. ourworldindata.org/grapher/full-list-cumulative-total-tests-perthousand-map?year=2020-05-10. Retrieved on 10-05-2020.

7. WHO. (2020) COVID-19 and Older People. Available from: https://www.who.int/news-room/q-a-detail/q-a-onon-covid-19-for-older-people. Retrieved on 13-05-2020.

8. Kluge, P.P. (2020) Statement-older People are at Highest Risk From COVID-19, But All Must Act to Prevent Community Spread. Available from: http://www.euro.who.int/en/ health-topics/health-emergencies/coronavirus-covid-19/statements/statement-older-people-are-at-highest-risk-from-covid -19,-but-all-must-act-to-prevent-community-spread?fbclid=IwAR0gKWhHbqCfq3GC5BYJ9Nogm_VGjOzRV2EVsyBhgqOqMGO9hKwh7uJ0Ls. Retrieved on 13-05-2020.

9. Statista. Elderly population in Italy. (2020) Available from: https://www.statista.com/statistics/785104/elderly-population-in-italy. Retrieved on 15-05-2020.

10. Nott, D. (2020) The COVID-19 response for vulnerable people in places affected by conflict and humanitarian crises. Lancet, 395(10236): 1532-1533.

11. National Center for Diseases Control. (2020) Geographical Distribution of COVID-19 in Libya. Available from: https:// www.geospatiallibya.maps.arcgis.com/apps/opsdashboard/index.html\#/3d76536249e0467d80541 fa0b3cb70b9. Retrieved on 25-05-2020.

12. Miller, A., Reandelar, M.J., Fasciglione, K., Roumenova, V., Li, Y. and Otazu, G.H. (2020) Correlation between universal BCG vaccination policy and reduced morbidity and mortality for COVID-19: An epidemiological study. MedRxiv, Doi: https://doi.org/10.1101/2020.03.24.20042937.

13. Sruthijith, K.K. and Bureau, E.T. (2020) BCG Vaccination Policies Make a Ten Times Difference in Covid-19 Incidence, Mortality: New Study. The Economic Times. Available from: https://www.m.economictimes.com/industry/healthcare/biotech/healthcare/nations-without-bcgvaccination-saw-higher-cases/articleshow/74956201.cms. Retrieved on 10-05-2020.

14. Kinoshita, M. and Tanaka, M. (2020) Impact of routine infant BCG vaccination on COVID-19. J. Infect., 81(4): 625-633.

15. Hamiel, U., Kozer, E. and Youngster, I. (2020) SARS$\mathrm{CoV}-2$ rates in BCG-vaccinated and unvaccinated young adults. J. Am. Med. Assoc., 323(22): 2340-2341.

16. Phan, T. (2020) Genetic diversity and evolution of SARSCoV-2. Infect. Genet. Evol., 81: 104260.

17. Korber, B., Fischer, W.M., Gnanakaran, S., Yoon, H., Theiler, J., Abfalterer, W., Foley, B., Giorgi, E.E., Bhattacharya, T., Parker, M.D., Partridge, D.G., Evans, C.M., Freeman, T.M., de Silva, T., LaBranche, C.C. and Montefiori, D.C. (2020) Spike mutation pipeline reveals the emergence of a more transmissible form of SARS-CoV-2. BioRxiv, Doi: https://doi.org/10.1101/2020.04.29.069054.

18. Kwok, K.O., Lai, F., Wei, W.I., Wong, S.Y.S. and Tang, J.W.T. (2020) Herd immunity-estimating the level required to halt the COVID-19 epidemics in affected. J. Infect., 80(6): e32-e33.

19. Wang, J., Tang, K., Feng, K., Lin, X., Lv, W., Chen, K. and Wang, F. (2020) High Temperature and High Humidity Reduce the Transmission of COVID-19. Available from: https://www. ssrn.com/abstract=3551767. Retrieved on 12-05-2020.

20. Sobral, M., Duarte, G.B., da Penha Sobral, A., Marinho, M. and de Souza Melo, A. (2020) Association between climate variables and global transmission of SARS-CoV-2. Sci. Total Environ., 729: 138997.

21. Mecenas, P., Bastos, R., Vallinoto, A. and Normando, D. (2020) Effects of temperature and humidity on the spread of COVID-19: A systematic review. MedRxiv, Doi: https://doi. org/10.1101/2020.04.14.20064923.

22. O'Reilly, K.M., Auzenbergs, M., Jafari, Y., Liu, Y., Flasche, S. and Lowe, R. (2020) Effective transmission across the globe: The role of climate in COVID-19 mitigation strategies. Lancet Planet. Health, 4(5): e172. 